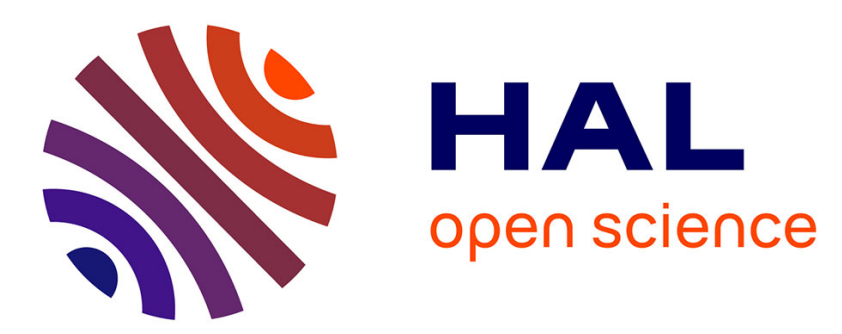

\title{
A simple and accurate electromagnetic model of a windturbine blade at radar frequency
}

Ludovic Claudepierre, Rémi Douvenot, Christophe Morlaas

\section{To cite this version:}

Ludovic Claudepierre, Rémi Douvenot, Christophe Morlaas. A simple and accurate electromagnetic model of a windturbine blade at radar frequency. ICEAA 2014, International Conference on Electromagnetics in Advanced Applications, Aug 2014, Palm Beach, Aruba. pp 253-256, 10.1109/ICEAA.2014.6903856 . hal-01073356

\section{HAL Id: hal-01073356 \\ https://hal-enac.archives-ouvertes.fr/hal-01073356}

Submitted on 9 Oct 2014

HAL is a multi-disciplinary open access archive for the deposit and dissemination of scientific research documents, whether they are published or not. The documents may come from teaching and research institutions in France or abroad, or from public or private research centers.
L'archive ouverte pluridisciplinaire HAL, est destinée au dépôt et à la diffusion de documents scientifiques de niveau recherche, publiés ou non, émanant des établissements d'enseignement et de recherche français ou étrangers, des laboratoires publics ou privés. 


\title{
A Simple and Accurate Electromagnetic Model of a Windturbine Blade at Radar Frequency
}

\author{
L. Claudepierre, R. Douvenot, and C. Morlaas*
}

\begin{abstract}
This paper proposes an electromagnetic model of a windturbine blade accurate at the civil aviation radar frequency. This new model is homogeneous and provides accurate results in scatterering problems.
\end{abstract}

\section{Introduction}

The fast-growing number of windturbines constrains manufacturers to implant the windfarms closer and closer to the minimum radar distance fixed by official regulations. Windturbines are large metallic and dielectric structures. They can be a real problem for electromagnetic devices working at radar frequencies (civil aviation, weather forecast...). The relaxation of these regulations could be possible with a trustful modelling of the impact of the windturbine farms.

In order to predict the contribution of this scatterers, scenarii with large windfarms have to be simulated. Masts and hubs are metallic but blades are dielectric. Each blade is made of three parts, each one is composed of several layers (three layers for the ENERCON structure [3]). Since simulating this structure requires huge memory resources, it has to be simplified. A common approximation is to consider blades as metallic [4].

We show that this hypothesis overestimates the impact of the windturbines and we pro-

${ }^{*}$ The authors are with ENAC, TELECOM/EMA, F-31055 Toulouse, France and Toulouse University, F-31400 Toulouse, France. E-mail: claudepierre@recherche.enac.fr pose to investigate a simplified structure with the same electromagnetic behavior. The simplification of the blade structure involves two steps. Firstly, the initial multilayer composition of the blade is replaced with an equivalent homogeneous dielectric material. Secondly the geometry of the blade is reduced to its most contributor part and compared to a metallic blade.

\section{Simplification of the material}

The simplification of the composition consists in substituting the real multilayer dielectric material by a one-layer dielectric, equivalent in terms of reflection and transmission. The same methodology as Morlaas et al. [1] is used. Optimization is operated on the permittivity and thickness of the one-layer material for reflection and transmission coefficients to match the ones of the real structure. The method is applied on a ENERCON windturbine blade. This blade is made of three parts (figure 1), each one constituted of a multilayer material. The simplifi-

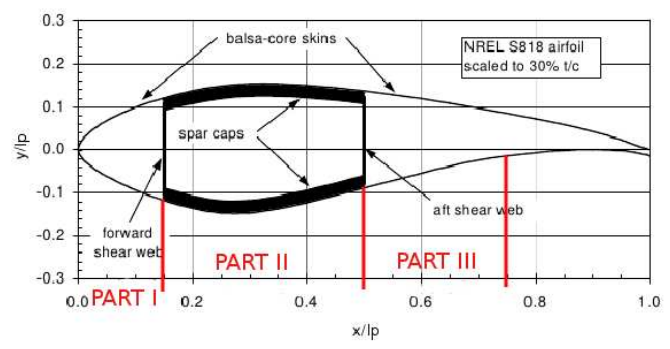

Figure 1: Geometry of the blade normalized by its length $l_{p}$ [2]

cation of the multilayer material is performed separately for each part of the blade. Reflection coefficients for TE and TM modes are plot- 
ted for the front (Part I), the spar (Part II), and the back (Part III) for a frequency of $1.3 \mathrm{GHz}$ in figures 2 to 4 . The one-layer modelling is

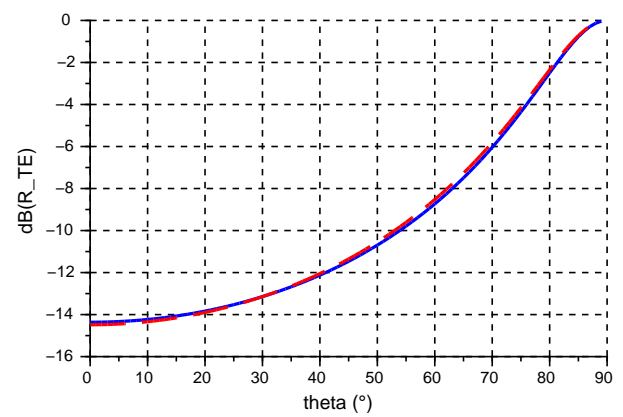

(a) $R_{T E}$

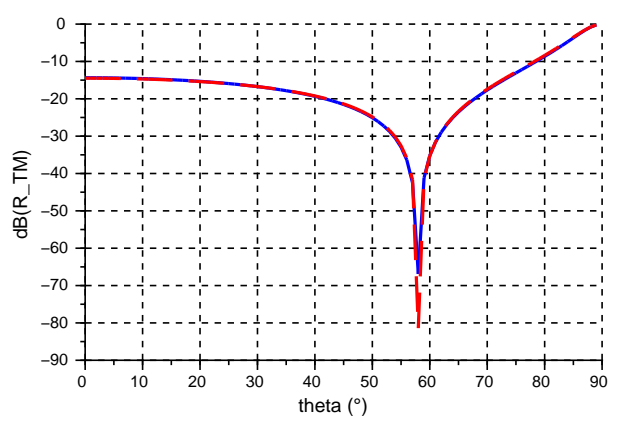

(b) $R_{T M}$

Figure 2: Reflection coefficients (dB) for TE (a) and TM (b) modes at $1.3 \mathrm{GHz}$ for the multilayer (dotted red), and one-layer (dotted blue) material from the front (part I) of the blade.

close to the multilayer material in terms of reflection (less than $1,5 \mathrm{~dB}$ of difference). So this simplification is considered accurate. More especially, it is more accurate than the metallic model $\left(R_{T M}=R_{T E}=0 \mathrm{~dB}\right.$ at all incidences).

These results correspond to the thicknesses and permittivities of the one-layer material summarized in table 1. According to the value of the reflection coefficients, the blade behaves similarly in TE and TM modes. Moreover, the main contributor in the scattering of the blade is the spar. Thus, the remain of the study over the geometry of blade has been made on the spar.

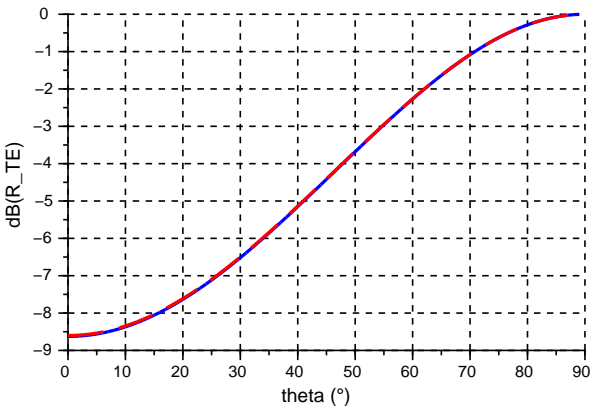

(a) $R_{T E}$

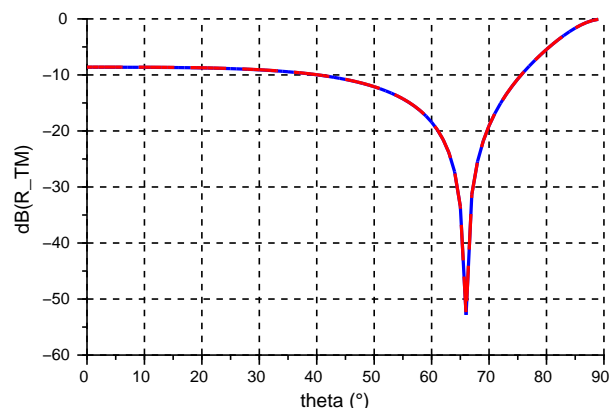

(b) $R_{T M}$

Figure 3: Reflection coefficients (dB) for TE (a) and TM (b) modes at $1.3 \mathrm{GHz}$ for the multilayer (dotted red) and one-layer (dotted blue) material from the spar (part II) of the blade.

\section{Simplification of the blade geometry}

Using the one-layer equivalent material allows to compute the scattered field of the blade on the commercial software FEKO with a standard computer. According to the previous conclusion, in this whole section the blade is reduced to its spar. The aim is to obtain a model with a simpler geometry but still accurate at radar frequency $(1.3 \mathrm{GHz})$ and with a precision better than $5 \mathrm{~dB}$ in every direction of observation and for every incidence. In order to reduce computing time, a reduced-length spar $(7.5 \mathrm{~m} \times 3 \mathrm{~m})$ is considered (figure 5$)$. The field scattered by a metallic and a dielectric reduced spars are computed and compared to the field scattered by a whole metallic reduced blade. As the winturbine and its blade can be placed anywhere from the radar, various directions of incidence have to be investigated. So a plane wave source is considered following the direc- 


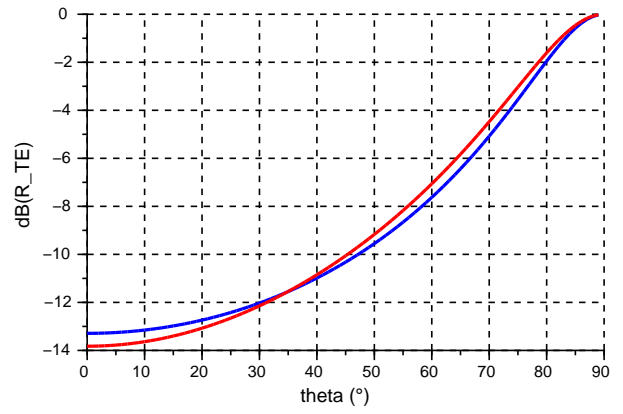

(a) $R_{T E}$

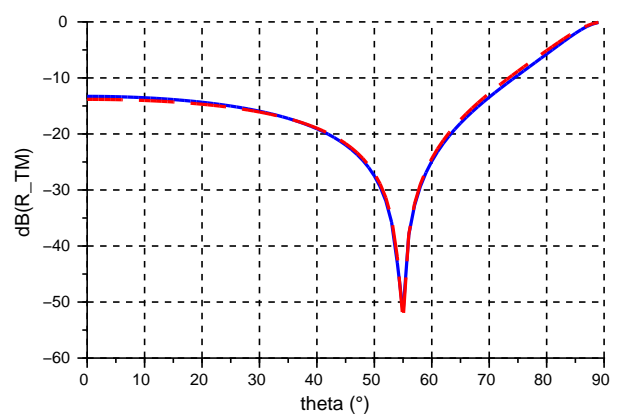

(b) $R_{T M}$

Figure 4: Reflection coefficients (dB) for TE (a) and TM (b) modes at $1.3 \mathrm{GHz}$ for the multilayer (dotted red) and one-layer (blue) material from the back (part III) of the blade.

tions $\theta=45^{\circ}$ and $\varphi=45^{\circ}, 90^{\circ}$. Representative results are plotted along two sections in figures 6 and 7 . The whole metallic blade overestimates the scattered fields $15 \mathrm{~dB}$ in some directions (figure $6(\mathrm{~b})$ ). On the other hand, the metallic spar underestimates $15 \mathrm{~dB}$ in some directions, and overestimates the scattered fields $10 \mathrm{~dB}$ in other directions as shown in figures 6 (a) and 7 (b). Thus, the two metallic structures are not sufficially accurate. These results prove that the dielectric charaterictic of the material is essential for a precise modelling of the blade. It also confirms the conclusion of the previous section about the dielectric behavior of the spar. Finally, the geometric simplification of the blade consists in reducing it to its spar.

\begin{tabular}{|l|c|c|}
\hline Blade part & $\varepsilon_{r}$ & thickness $(\mathrm{mm})$ \\
\hline front & 2.55 & 9.5 \\
\hline spar & 5 & 43.98 \\
\hline back & 2.1 & 17.6 \\
\hline
\end{tabular}

Table 1: Characteristic dimensions of the extern layer of the blade for each part

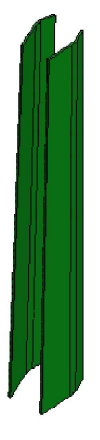

Figure 5: CAD modelling of the reduced spar

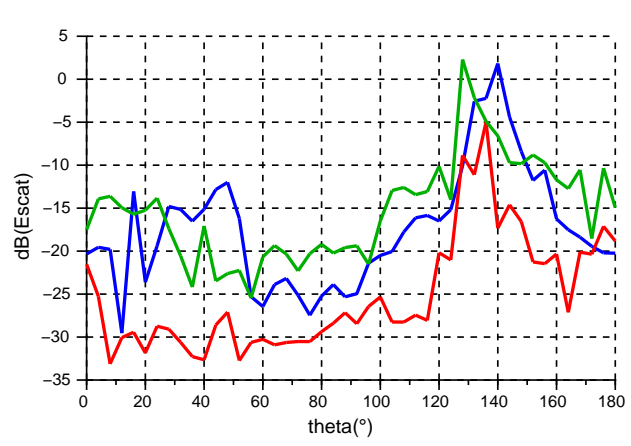

(a) Scattered field observed in the plane $\varphi=44^{\circ}$.

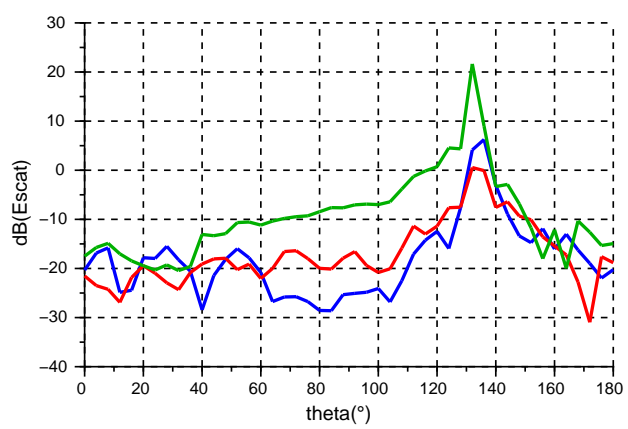

(b) Scattered field observed in the plane $\varphi=92^{\circ}$.

Figure 6: Scattered field (dB) for a dielectric (blue) and metallic (red) reduced spar, and metallic reduced blade (green) with an incident plane wave with $\theta=45^{\circ}$ and $\varphi=45^{\circ}$. 


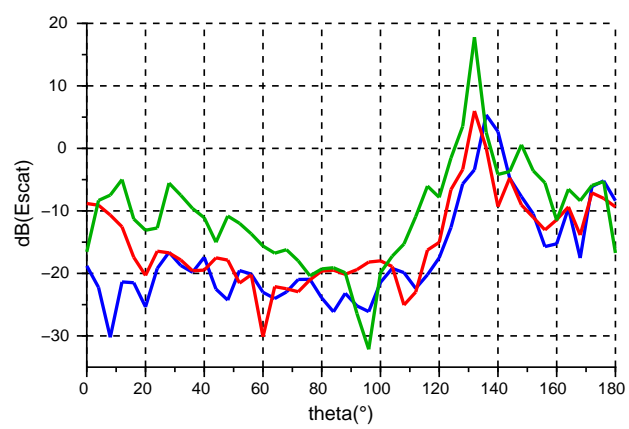

(a) Scattered field observed in the plane $\varphi=44^{\circ}$.

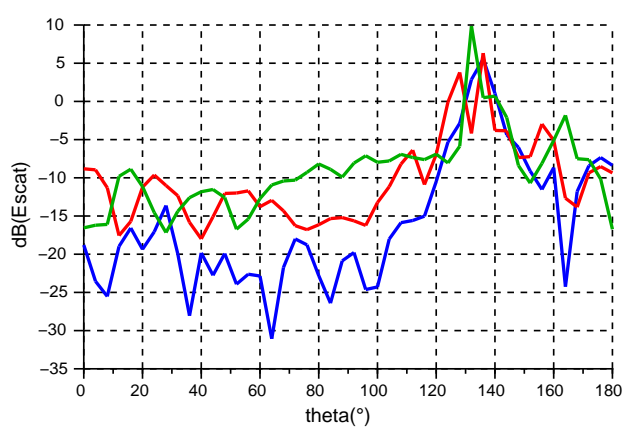

(b) Scattered field observed in the plane $\varphi=92^{\circ}$.

Figure 7: Scattered field (dB) for a dielectric (blue) and metallic (red) reduced spar, and metallic reduced blade (green) with an incident plane wave with $\theta=45^{\circ}$ and $\varphi=90^{\circ}$.

\section{Conclusion}

We have proposed a homogeneous model of the windturbine blade at civil aviation radar frequency of $1.3 \mathrm{GHz}$. The blade has been reduced to its spar made of an equivalent dielectric material. It is the only part having a significant electromagnetic impact. Using this model, we demonstrate the unrelevancy of using metallic surfaces to precisely compute the field scattered by the spar. Nevertheless, the metallic modelling can be used as a coarse approximation when only an estimation of the main scattering direction is required.

The same methodology can be applied to other frequencies, particularly at $2.7 \mathrm{GHz}$ which is also used in radar detection, in order to obtain a simple and accurate model of this windturbine blade.

\section{References}

[1] C. Morlaas, M. Fares, and B. Souny. Wind turbine effects on VOR system performance. IEEE Aerospace and Electronics Systems Magazine, 44:1464-1476, 2008.

[2] M. Morlaas, C. Fares. Étude de la précision VOR au voisinage d'éoliennes. Technical report, ENAC / CERFACS, 2007.

[3] G. J. Poupart. Wind farms impact on radar aviation interests - final report. Technical report, QinetiQ, 2003. Appendix A-2.

[4] O.M. Yucedag and H.A. Yucedag, S.M. Serim. Radar cross section calculation of a wind turbine modeled by PEC canonical structures. Conference on Electrical and Electronics Engineering (ELECO), 2013 8th International, pages 562-565, Nov 2013. 